\title{
Struktur Nuklir: Halo dan Pairing pada Neutron Rich Nuclei
}

\section{Nuclear Structure: Halo and Pairing In Neutron Rich Nuclei}

\author{
Alpi Mahisha Nugraha \\ Program Studi Informatika, Fakultas Teknik dan Ilmu Komputer, Universitas Indraprasta PGRI Jakarta
}

Alamatemail: alpi.mahisha@gmail.com

\begin{abstract}
Abstrak - Fenomena halo dan pairing merupakan perilaku unik dari neutron yang terdapat pada suatu inti atom. Halo neutron dalam nuklir digambarkan adanya kemunculan 'ekor' dan adanya 'ruang kosong' antara core dan ekor pada distribusi neutron akibat energi ikat yang lemah sedangkan pairing adalah fenomena kolektif yang terjadi akibat neutron yang berlebih dalam inti atom berpasangan. Fenomena pairing atau pasangan mengakibatkan perubahan energi ikat inti atom, fenomena ini dapat terlihat jelas pada nuklida dan isotop dengan jumlah neutron genap. Umumnya fenomena halo merupakan fenomena yang muncul akibat adanya faktor repulsif dalam inti atom sedangkan fenomena pairing diakibatkan faktor attraktif. Kedua fenomena ini bukanlah merupakan fenomena yang kontradiktif namun dapat muncul secara bersamaan dalam suatu nuklida terutama pada neutron rich nuclei atau inti atom yang kaya dengan neutron seperti isotop Sn.
\end{abstract}

Kata kunci: fenomena halo, pairing effect, neutron rich nuclei

\begin{abstract}
Halo and pairing neutrons is a unique behavior phenomenon in an atomic nucleus. Halo neutrons in nuclear are described as exists tails and empty space between cores and tails in the neutron density caused the weakness of binding energy, whereas pairing is a collective phenomenon that occurs due to excess neutrons in paired nuclei. Pairing phenomenon results a change in the energy of the atomic nucleus, this phenomenon can be seen clearly in nuclides and isotopes with an even number of neutrons. Generally the halo phenomenon is a phenomenon that arises due to the presence of repulsive factors in the nucleus while the pairing phenomenon is caused by an attractive factor. These two phenomena aren't contradictory phenomena but can exist simultaneously in a nuclide, especially in neutron rich nuclei such as Sn isotope.
\end{abstract}

Keywords: halo phenomenon, pairing effect, neutro rich nuclei

(C) 2020 Jurnal Jejaring Matematika dan Sains. This work is licensed under a $\underline{\text { CC BY-NC 4.0 }}$

\section{PENDAHULUAN}

Salah satu kemajuan besar dalam eksperimen sains nuklir beberapa dekade ini adalah penembakkan nuklir radioaktif atau Radioactive Nuclear Beams (RNB). Eksperimen yang dilakukan dengan menembakkan nuklir ini dapat memungkinkan kita untuk melihat lebih jauh mengenai perilaku nuklir di wilayah yang belum tereksplorasi pada tabel periodik. Beragam model mengenai fenomena dalam inti atom muncul seiring dengan banyaknya data yang dihasilkan dari eksperimen RNB ini.

Kemajuan eksperimen ini juga membuka kesempatan untuk mempelajari fenomena nuklir yang jauh dari pulau kestabilan. Seperti inti atom dengan jumlah neutron yang melimpah atau yang dikenal dengan neutron rich nuclei, beberapa fenomena yanng muncul pada inti atom saat keadaan ini adalah fenomena halo dan fenomena pairing.

Fenomena halo adalah fenomena yang diakibatkan karena distribusi proton atau pun neutron yang tidak homogen dalam nuklir, fenomena halo dapat digambarkan dengan adanya penambahan 'ekor' dan adanya 'ruang kosong' antara core dan ekor pada distribusi proton atau pun neutron akibat energi ikat nukleon yang lemah [1]. Hal ini dikarenakan adanya distribusi nukleon yang tidak homogen. Fenomena halo dapat dimodelkan seperti pada Gambar 1, fenomena yang menunjukkan adanya gap antara ekor dengan core pada nuklida ${ }^{11} L i$.

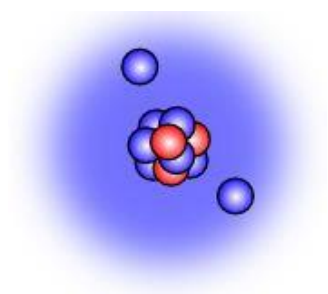
Gambar 1. Fenomena Halo pada ${ }^{11} \mathrm{Li}$
(sumber: TRIUMF Canada's particle accelerator centre)

Salah satu teori untuk menghitung besaran yang terkait dengan fenomena halo adalah teori Helm [2]. Pada mulanya teori Helm digunakan untuk menganalisa fenomena inelastik dan elastik hamburan elektron pada nuklir genap-genap [3]. Sayangnya, penggunaan teori ini dalam analisa fenomena halo memiliki beberapa keterbatasan, kemudian terdapat pendekatan lain dalam 
menghitung besaran halo yang telah digunakan untuk menghitung halo neutron pada isotop Sn [4].

Penggunaan pendekatan tersebut tetap memerlukan model dalam menghitung properti inti atom. Hingga saat ini, model RMF merupakan salah satu model yang cukup baik dalam menghitung properti nuklir dan melihat beberapa fenomena nuklir. Prinsip sederhana dari model RMF adalah anggapan bahwa sifat-sifat dari partikel tunggal dan nuklir dapat ditentukan oleh harga rata-rata (mean) dari kontribusi setiap penyusunnya yakni proton dan neutron (nukleon) [5]. Besaran properti nuklir yang dihasilkan dengan menggunakan model ini melibatkan interaksi kuat yang terjadi pada nuklir, yang dimodelkan dalam bentuk pertukaran meson antar nukleon dalam nuklir.

\section{METODE PENELITIAN}

Pendekatan teori yang berbeda dalam menganalisa fenomena pairing. Semakin banyak jumlah neutron pada inti atom beberapa fenomena kolektifitas akan muncul, untuk menyelesaikan masalah berupa perhitungan energi total diperlukan suatu teori yang dapat menjelaskan interaksi yang melibatkan banyak partikel dan efek kolektifitas tersebut, seperti fenomena pairing. Pendekatan yang dapat digunakan untuk menjelaskan fenomena berupa superkonduktivitas dan superfluiditas adalah teori BCS yang dikemukakan oleh Bardeen, Cooper, dan Schrieffer [6].

Teori ini mula-mula diaplikasikan pada zat padat untuk menjelaskan fenomena superkonduktivitas pada logam. Namun seiring dengan perkembangan zaman, ternyata teori ini dapat digunakan untuk menyelesaikan permasalahan pasangan pada partikel fermion apa saja, termasuk untuk neutron maupun proton pada inti atom.

Pada penelitian ini menggunakan dua pendekatan yang berbeda dalam mengaproksimasi kedua fenomena antara fenomena halo dan pairing. Pada fenomen halo, fenomena halo dihitung menggunakan analisa properti inti atom yaitu distribusi neutron yang merupakan fungsi dari jari-jari inti atom itu sendiri. Untuk menghitugnya digunakan pendekatan atau teori relativistic mean field, yaitu teori medan rata-rata relativistik yang dapat menggambarkan bagaimana interaksi nukleon, ferrmion beserta suku-suku lainnya di dalam inti atom.

$$
\begin{aligned}
E_{\mathrm{RMF}}= & \int \sum_{j=1}^{A} \overline{\psi_{k}} \gamma_{0}\left[-i \vec{\gamma} \bar{\nabla} \gamma_{0}+\left(M \gamma_{0}-\mathrm{g}_{\sigma} \phi \gamma_{0}\right)+\left(\mathrm{g}_{\omega} V_{0}+\frac{1}{2} \mathrm{~g}_{\rho} R_{0} \tau_{0}\right)-\mathrm{g}_{\delta} \vec{d} \tau_{0} \gamma_{0}\right. \\
& \left.-\frac{f_{\omega}}{M} V^{0} \bar{\nabla} \frac{1}{2} \gamma_{\mu} \gamma_{\nu} \gamma_{0}-\frac{f_{\rho}}{2 M^{2}} R^{0} \bar{\nabla} \tau \frac{1}{2} \gamma_{\mu} \gamma_{\nu} \gamma_{0}+e A_{0} \frac{1+\tau_{0}}{2}\right] \psi_{k} d^{3} r \\
& -\int d^{3} r\left\{-\frac{1}{2} \mathrm{~g}_{\sigma} \phi \rho_{s}+\frac{k_{3}}{12 M} \mathrm{~g}_{\sigma} m_{\sigma}^{2} \phi^{3}+\frac{k_{4}}{24 M^{2}} \mathrm{~g}_{\sigma}^{2} m_{\sigma}^{2} \phi^{4}+\frac{1}{2} \mathrm{~g}_{\omega} V_{0} \rho_{o}\right. \\
& -\frac{1}{24} \zeta_{0} \mathrm{~g}_{\omega}^{2} V_{0}^{4}+\frac{1}{4} \mathrm{~g}_{\rho} R_{0} \rho_{o, o}-\frac{\eta_{2 \rho}}{4 M^{2}} \mathrm{~g}_{\omega}^{2} m_{\rho}^{2} V_{0}^{2} R_{0}^{2}-\frac{5 f_{\omega}}{2 M} V_{0} \rho_{o}^{T}-\frac{5 f_{\rho}}{4 M^{2}} R_{0} \rho_{o, o}^{T} \\
& -\frac{1}{2} \mathrm{~g}_{\delta} \vec{d}_{s, o}+\frac{1}{2} e A_{0} \rho_{p, o} \\
& +C_{\text {exc }}^{\mathrm{EM}}\left[\frac{3}{4} e^{2}\left(\frac{3}{\pi}\right)^{\frac{1}{3}}\right] \rho_{p}^{\frac{4}{3}}\left[1-\frac{2}{3 M^{2}}\left(3 \pi^{2}\right)^{\frac{2}{3}} \rho_{p}^{\frac{2}{3}}\right] .
\end{aligned}
$$

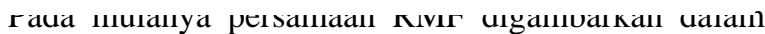
bentuk kerapatan Lagrangian yang terdiri dari beberapa suku, seperti suku interaksi nukleon, interaksi meson, suku linear, suku non linear dan beragam interaksi meson lainnya. Sehingga diperoleh persamaan kerapatan energi dari penurunan persamaan Hamiltoniannya yang ditunjukkan oleh persamaan (1).

Persamaan (1) merupakan persamaan kerapatan energi, kemudian persamaan energi ini akan diiterasi sehingga memperoleh besar properti dari inti atom yang akan dianalisa terpisah untuk menghitung fenomena halo neutron pada isotop Sn. Besaran yang mengindikasikan fenomena halo neutron adalah perbedaan antara jari-jari $R_{r m s}$ (root mean square) dari core $\left(R_{r m s-c o r e}\right)$ dan total inti atom $\left(R_{\text {rms-total }}\right)$. Sedangkan untuk menganalisa fenomena pairing digunakan model perhitungan Bardeen-CooperScrieffer (BCS) dengan potensial interaksi antar tingkat energi bernilai tetap [7]. Adapun persamaan Hamilotnian untuk pada teori BCS sebagai berikut:

$$
E=\langle B C S|H| B C S\rangle=2 \sum_{s>0} \varepsilon_{s}^{0} v_{s}^{2}+\sum_{s s^{\prime}>0} V_{s s^{\prime}} u_{s} v_{s} u_{s^{\prime}} v_{s^{\prime}}+\sum_{s>0} V_{s s^{\prime}} v_{s}^{2}
$$

dengan suku pertama mempresentasikan energi tunggal, sedangkan kedua suku selanjutnya adalah suku yang mepresentasikan pairing dengan potensial interaksi Vss'.

Level yang digunakan fokus pada lima level terluar pada isotop Sn dengan potensial interaksi antar level di set pada nilai $0.05,0.1$, dan 0.5 . Besaran yang digunakan untuk mengindikasi fenomena pairing adalah gap pairing atau delta dengan satuan $\mathrm{MeV}$ sebagai berikut:

$$
\Delta_{s}=\frac{1}{2} \sum_{s^{\prime}>0} \frac{\Delta_{s \prime}}{\varepsilon_{s \prime}} V_{s s t}
$$

Hasil dari kedua pendekatan ini akan dianalisa untuk mengetahui korelasi anatara fenomena halo dan fenomena pairing yang terjadi pada inti atom isotop Sn.

\section{HASIL DAN PEMBAHASAN}

Isotop $\mathrm{Sn}$ atau Tin merupakan isotop yang sampai saat ini menjadi objek penelitian di skala eksperimen laboratorium karena karakteristiknya yang memiliki kestabilan tinggi terutama saat kondisi inti atom closed shell. Isotop Sn merupakan salah satu isotop inti ringan yang cukup sering digunakan sebagai standar prsesisi suatu pendekatan model baru seperti halnya untuk meninjau fenomena halo dan pairing yang terjadi pada inti atom.

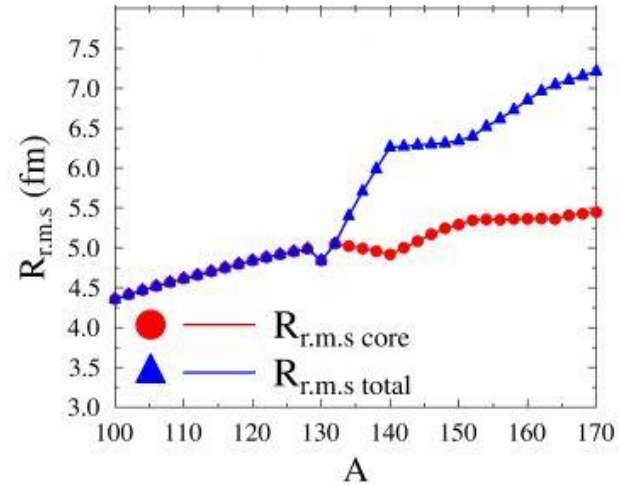

Gambar 2. Fenomena halo pada Isotop Sn

Fenomena halo pada isotop Sn terlihat pada Gambar 2. $R_{\text {rms-core }}$ adalah jari-jari rms dari pusat inti atom sedangkan $R_{\text {rms-total }}$ adalah jari-jari rms total dari inti atom sehingga perbedaan kedua nilai inilah yang mengindikasikan adanya ruang kosong antara core dengan ekor akibat energi ikat yang lemah. 
Terlihat bahwa awal mula terbentuknya fenomena halo neutron muncul pada isotop $\mathrm{Sn}$ setelah melewati kondisi closed shell-nya pada isotop ${ }_{50}^{132} S n$. Pada ${ }_{50}^{132} S n$ nilai $R_{\text {rms-total }}$ mengerut yang menandakan kondisi inti atom yang tertutup dan mengindikasikan energi ikat yang kuat. Namun setelah melewatinya perbedaan antara nilai $R_{\text {rms-core }}$ dengan $R_{\text {rms-total mulai muncul dan semakin }}$ memebesar seiring dengan bertambahnya jumlah neutron pada inti isotop Sn. Semakin besar nilai perbedaan ini mengartikan bahwa ruang kosong dalam inti atom semakin besar.

Pada Gambar 2 terlihat karakteristik dari fenomena halo tidaklah linear seiring dengan bertambahnya jumlah neutron, terdapat titik dimana ruang kosong pada isotop $\mathrm{Sn}$ bertambah terus menerus dan berkurang pada isotop tertentu seperti pada isotop ${ }_{50}^{140} \mathrm{Sn}$ yang menjadi titik stop kenaikan jarak ruang kosong pada inti atom untuk sesaat.

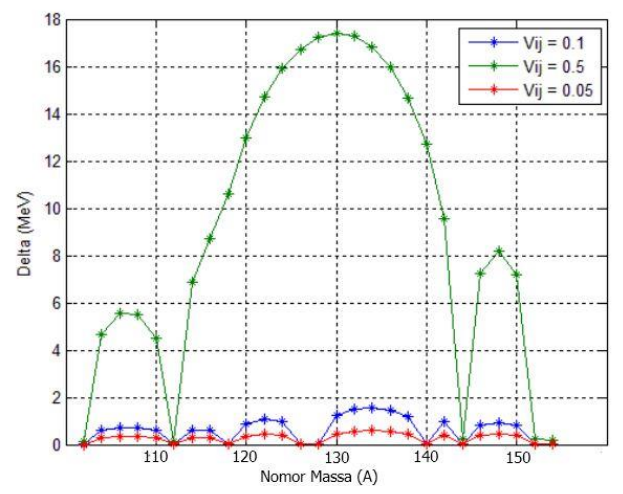

Gambar 3. Gap pairing pada Isotop $S n$

Fenomena pairing pada isotop $\mathrm{Sn}$ terlihat pada Gambar 3. Nilai delta atau gap pairing merupakan besaran yang dapat mempersentasikan fenomena pairing pada Isotop Sn. Vij atau Vss' merupakan matriks interaksi yang menggambarkan besarnya interaksi akibat pairing tiap levelnya. Pada penelitian ini digunakan lima level energi yakni orbit $g_{1 / 2}, d_{5 / 2}, d_{3 / 2}, s_{1 / 2}$, dan $h_{11 / 2}$.

Pada Vij bernilai 0.05 dan 0.1 masih terlihat bahwa isotop Sn membentuk lima kumpulan energi sesuai dengan model yang digunakan. Pada nilai Vij yang relatif kecil ini interaksi pairing anatar level belum besar sehingga inti atom masih terlihat lim akumpulan seperti pada Gambar 3. Berbeda ketika Vij bernilai 0.5 yang cukup besar, beberapa kumpulan bergabung dan menyisakan tiga kumpulan besar yang mengindikasikan fenomena pairing yang sangat besar. Semakin besar nilai Vij maka bentuk inti atom akan menyatu menjadi satu kumpulan besar.

Fenomena ini seolah-olah merupakan hal yang berlawanan dengan fenomena halo pada pembahasan sebelumnya. Seiring dengan pertambahan neutron fenomena halo dan pairing menjadi semakin terlihat. Terlebih lagi ketika isotop telah melewati closed shellnya, artinya halo dan pairing merupakan fenomena yang berlangsung bersamaan alih-alih fenomena yang kontradiktif meskipun kedua karakter dari fenemona tersebut berbeda, yakni pairing membuat energi ikat inti atom semakin kuat sedangkan halo membuat energi ikat inti atom semakin lemah.

\section{SIMPULAN}

Berdasarkan hasil penelitian dan pembahasan pada pembahasan sebelumnya, dapat disimpulkan bahwa fenomena halo dan pairing bukanlah merupakan fenomena pasangan kontradiktif namun dapat muncul pada saat bersamaan meskipun secara pendekatan yang diperoleh bahwa fenomena halo mengindikasikan energi inti atom yang lemah, berbeda dengan fenomena halo, pairing yang muncul mengakibatkan inti atom memiliki energi ikat yang kuat. Hakikatnya fenomena halo muncul akibat energi ikat inti atom yang lemah, sedangkan fenomena pairing membuat energi ikat inti atom menjadi semakin kuat. Seiring dengan jumlah neutron yang bertambah kedua fenomena ini muncul dengan karakternya masing-masing pada isotop $\mathrm{Sn}$. Kedua fenomena ini sekilas dapat menggambarkan interkasi yang sosial yang terjadi manusia ketika hidup berkelompok dan individu sehingga bukanlah hal yang tidak mungkin mendekati perilaku sosial manusia dengan teori yang diterapkan pada inti atom.

\section{REFERENSI}

[1] Misu, et al. 'Deformed nuclear halos', Nucl Phys. A614, Hal: 44-70, 1997.

[2] Mizutori, et al. 'Nuclear skins and halos in the meanfield theory', Phys. Rev. C61, No. 044326, 2000.

[3] Helm, Richard H. 'Inelastic and Elastic Scattering of 187-Mev Electrons from Selected Even-Even Nuclei', Phys. Rev. Vol 104, No 5, 1956.

[4] Rotival, et al. 'Halo phenomenon in finite manyfermion systems: Atom-positron complexes and largescale study of atomic nuclei', Phys. Rev C, Vol 79, No 054309, 2009.

[5] Liliani, et al. 'Impacts of the tensor couplings of omega and rho mesons and Coulomb-exchange terms on supe-rheavy nucleiand their relation to the symmetry energy', Physical review C, Vol 93, No. 054322, May 2016.

[6] Bardeen, L. N. Cooper, and J. R. Schrieffer. 'Microscopic Theory of Superconductivity', Phys. Rev. 106: 162-164, 1957.

[7] Nugraha, A.M. 'Efek Pairing pada Isotop Sn (N>82) dalam Teori BCS Menggunakan Sembilan Tingkat Energi', Faktor Exacta, Vol 10, No 2, Hal: 101-110, 2017. 